\title{
Loss of Chromosome 17p
}

National Cancer Institute

\section{Source}

National Cancer Institute. Loss of Chromosome 17p. NCI Thesaurus. Code C36499.

A cytogenetic abnormality that refers to the loss of all or part of the short arm of chromosome 17 (17p). 